\section{Archaeological split}

SIR-Much has been made of the 'great success' that attended the breakaway 'World Archaeological Congress' held at Southampton in September 1986. According to information one of us has received from the chairman of that meeting, "over 1,000 people registered from about 100 countries".

It is important to place these figures in perspective. The attendance of 1,000 contrasts sharply with the $2,000-3,000$ that the organizers originally expected. Moreover, we would remind our colleagues that at the IXth Congress of the International Union of Prehistoric and Protohistoric Sciences (IUPPS), held at Nice from 13 to 18 September 1976, which, in accordance with the constitution of IUPPS, was open to scientists from all countries, 3,127 participants from 94 countries were present.

So, at the price of holding a meeting by sacrificing a major principle, the organizers gained five or six countries, lost 2,000 participants and did grievous harm to British and world archaeology. Add to that the unprecedented split in British and world archaeology, the wedge driven between colleague and colleague, the stimulus given to a major cleavage and politicization of world sciences ... and we cannot see that all this adds up to 'a great success'.

HENRY DE LUMLEY

Museum National d'Histoire Naturelle,

Paris, France

Department of Anatomy,

Phillip V. Tobias

University of the Witwatersrand,

Johannesburg, South Africa

\section{Throwing stones?}

SIR-Your correspondent Vera Rich never misses a chance to revel in schadenfreude at any misfortune that befalls the Soviet Union, which she immediately attributes to inadequate planning or ability to cope by the authorities. The latest outburst was her report (Nature 325, 188; 1987) of the spell of very cold weather that hit most of Europe between 11 and 16 January.

I have visited the Soviet Union three times during very cold winters and was impressed by the way buildings (including private homes) were heated, streets and railways kept free of snow. All forms of public transport ran efficiently, and diesel vehicles had preheated fuel and oil.

I was in England during this year's cold spell and was appalled by the inability of the authorities there to cope. Many roads, including some motorways, were closed, there was chaos on the railways and old people were dying of hypothermia in their homes, all this at temperatures $30^{\circ} \mathrm{C}$ above what the Russians were experiencing. The military managed to overturn a vehi- cle carrying a nuclear weapon, an event that might well have developed into a catastrophe of Chernobyl proportions.

Maybe there is some Vera Rich in the Soviet Union churning out pejorative copy about the inability of the capitalist authorities to cope with a spell of only slightly cold weather, and their callous disregard of the plight of their citizens. But what such a correspondent would write could genuinely be classified as pravda.

Institute of Cell Research

ROBERT BYWATER

Biomedical Centre, Box 596 ,

S-75124 Uppsala, Sweden

\section{Space colonization}

SIR-Von R. Eshleman's reservations about the near-term feasibility of space colonization deserve attention (Nature 324, $115 ; 1986)$. Colonization historically has been successful when existing technology permitted the migration of substantial numbers of people into large uncultivated areas that were suitable for agriculture. Conversely, experience has shown that the exploitation of a hostile environment for commercial or scientific purposes does not result in colonization. For example, the mapping of the ocean floor and offshore oil drilling have not resulted in any noticeable increase in the population of the oceans.

The rest of our Solar System is not suitable for agriculture. If the colonization of 'space' is judged to be a worthwhile goal, one way to proceed would be to use remote sensing devices to identify Earthlike planets in other Solar Systems. Once an Earth-like environment has been identified, it would be appropriate to initiate plans for colonization. An attempt to colonize the rest of our Solar System would probably be as cost effective and as successful as the European colonization of Greenland from AD 986 to 1599 .

RoBert SHEPHERD 12216 NW Barnes Road, Apartment 139, Portland, Oregon 97229, USA

\section{More vaccine needed}

SIR-The article by Tim Beardsley describing the formation and goals of the Task Force on Hepatitis B Immunization (Nature 324, 399; 1986) may inadvertently give the impression that we intend to achieve widespread hepatitis-B virus (HBV) immunization in high prevalence regions of the world solely through use of the vaccine produced by the Cheil Sugar Co. in Seoul, Korea.

That company deserves credit for having produced a pure and potent vaccine that can be manufactured at relatively low cost. Moreover, because of the generosity and humanitarian spirit of $\mathrm{Mr}$ B.C. Lee, chairman of Cheil's parent company, SAMSUNG, it is the first to commit itself to providing vaccine for public sector mass immunization programmes at $\$ 1.00$ per dose, the maximum cost for a vaccine to be considered for inclusion in mass immunization programmes.

But the actual need for $\mathrm{HBV}$ vaccine throughout the world will be several hundred million doses a year, so it is clearly necessary for many producers to share responsibility for meeting these needs.

The Task Force is therefore in communication with all potential manufacturers of HBV vaccine, from whom we hope to be able to elicit similar commitments.

The Task Force favours widespread use of all safe, effective and affordable vaccines so that hepatocellular carcinoma and cirrhosis in high prevalence regions of the world can be controlled.

Alfred M. Prince

(Chairman)

Task Force on Hepatitis B Immunization, Lindsley $F$. Kimball Research Institute of the New York Blood Center,

310 East 67th Street,

New York, NY 10021, USA

\section{Valuable libraries}

SIR-As users of the human chromosomespecific libraries prepared by the Los Alamos and Livermore National Laboratories of the Department of Energy and distributed by the American Type Culture Collection, we wish to refute the suggestion that these libraries are not of value to molecular geneticists (Nature 323, 660; 1986). In our experience these libraries represent a valuable and freely available resource. Their "deficiencies" reflect a state of the art problem. There is no doubt in our minds about the "biological talent" of the scientists involved, nor of the usefulness of the libraries.

Kay E. Davies

Nuffield Department of Clinical Medicine, John Radcliffe Hospital,

Headington, Oxford, UK

$$
\text { James F. Gusella }
$$

Harvard Medical School,

Massachusetts General Hospital,

Boston, Massachusetts 02114, USA

Department of Genetics, LAP-ChEe Tsui

Hospital for Sick Children,

Toronto, Ontario, Canada, M5G 1 X8

R. WILLIAMSON

Biochemistry Department,

St Mary's Hospital Medical School,

London W2, UK

Whitehead Institute for

David C. Page

Biomedical Research,

Nine Cambridge Center,

Cambridge, Massachusetts 02142, USA

M.A. Ferguson-SMith

Duncan Guthrie Institute of

Medical Genetics,

Royal Hospital for Sick Children,

Yorkhill, Glasgow G3 8SJ, UK 